\title{
Potential Impact of the Multi-Target Drug Approach in the Treatment of Some Complex Diseases
}

This article was published in the following Dove Press journal: Drug Design, Development and Therapy

\author{
Xolani H Makhoba' \\ Claudio Viegas Jr $\mathbb{D}^{2}$ \\ Rebamang A Mosa $\mathbb{D}^{1}$ \\ Flávia PD Viegas $\mathbb{D}^{2}$ \\ Ofentse J Pooe $\mathbb{1}^{3}$ \\ 'Department of Biochemistry, Genetics \\ and Microbiology, Division of \\ Biochemistry, University of Pretoria, \\ Hatfield, South Africa; ${ }^{2}$ Laboratory of \\ Research in Medicinal Chemistry \\ (PeQuiM), Institute of Chemistry, Federal \\ University of Alfenas, Alfenas, MG, Brazil; \\ ${ }^{3}$ Discipline of Biochemistry, School of Life \\ Sciences, University of KwaZulu-Natal, \\ Durban, South Africa
}

\begin{abstract}
It is essential to acknowledge the efforts made thus far to manage or eliminate various disease burden faced by humankind. However, the rising global trends of the socalled incurable diseases continue to put pressure on Pharma industries and other drug discovery platforms. In the past, drugs with more than one target were deemed as undesirable options with interest being on the one-drug-single target. Despite the successes of the singletarget drugs, it is currently beyond doubt that these drugs have limited efficacy against complex diseases in which the pathogenesis is dependent on a set of biochemical events and several bioreceptors operating concomitantly. Different approaches have thus been proposed to come up with effective drugs to combat even the complex diseases. In the past, the focus was on producing drugs from screening plant compounds; today, we talk about combination therapy and multi-targeting drugs. The multi-target drugs have recently attracted much attention as promising tools to fight against most challenging diseases, and thus a new research focus area. This review will discuss the potential impact of multi-target drug approach on various complex diseases with focus on malaria, tuberculosis (TB), diabetes and neurodegenerative diseases as the main representatives of multifactorial diseases. We will also discuss alternative ideas to solve the current problems bearing in mind the fourth industrial revolution on drug discovery.
\end{abstract}

Keywords: multi-target drugs, malaria, diabetes, tuberculosis and drug discovery

\section{Introduction}

Drug discovery and design has never been static, but continually more dynamic in response to increasing global morbidity and mortality rates caused by the so-called incurable diseases. Traditionally, the discovery of therapeutic drugs has been exploited based on the design of highly selective chemical entities to target a single biological entity, considered as a dominant player in a certain pathology. ${ }^{1,2}$ Using this strategy, researchers have expected to avoid any undesired side effects and guarantee a more drug-like property of drug candidates. However, highly selective or specific therapeutic agents directed to single molecular targets have proven to lack in efficacy, especially for complex diseases. The highly selective therapeutic agents have also been associated with the increasing incidences of drug resistance.

It is undeniable that the single-target drug strategy has had, over a long time, countless successes for the Pharma industry and the treatment of diseases, paving the current stage of evolution in therapeutics. ${ }^{3-12}$ For example, drugs such as artemisinin,
Correspondence: Xolani H Makhoba Department of Biochemistry, Genetics and Microbiology, Division of

Biochemistry, University of Pretoria, Hatfield 2000, South Africa

$+27124204149$

Email zolanimakhoba53@gmail.com

Ofentse J Pooe

Discipline of Biochemistry, School of Life Sciences, University of KwaZulu-Natal,

Private Bag X5400I, Durban 4000, South Africa

Tel +273I 2607664

Email PooeO@ukzn.ac.za 
and chloroquine have been traditionally used for the treatment of malaria. On the other hand, while insulin continues to be the most utilized form of treatment for type-1 diabetes, several oral hypoglycemic drugs are utilized in the management of type- 2 diabetes. Carboplatin, adriamycin and fluorouracil are amongst the most popular drugs for cancer treatment. However, due to the limited efficacy of singletarget drugs against multifactorial diseases in which the pathogenesis is dependent on a set of biochemical events and several bioreceptors operating concomitantly, strategies in drug design had to be reviewed. In this context, during the last years, medicinal chemistry has searched for new tools and alternatives capable of reaching more agility, security and a more efficient direction in the design and prospection of drug candidates.

The search for better results in clinical practices, because of lack of inefficacy of some treatments based on single drugs, has encouraged the adoption of polypharmacology as a new therapeutical strategy. Polypharmacology can be defined as the design or use of pharmaceutical agents that act on multiple molecular targets or multiple biochemical pathways. This multi-target approach comes in different forms, which could be association of drugs, combination of drugs or a single drug with multiple ligands, all intended for multiple targets. The combination therapy could be exemplified by the HIV/AIDS treatment, some types of cancer, tuberculosis, and hypertension. ${ }^{13-15}$ However, the inefficiency, deleterious effects from drug-drug interactions, distinct pharmacokinetics, toxicity, solubility, bioavailability and costs of combination therapy have reinforced the emergence of novel strategies in drug discovery. The most recent approach is now considering single drugs that concomitantly recognize more than one molecular target. This latest strategy advocates the combination, in a single scaffold, of different structural subunits that allow the molecular recognition by more than one bioreceptor, acting in a simultaneous mode in multiple targets interconnected to biochemical networks responsible for the pathophysiology of multifactorial diseases. $^{5-7}$

In this review, we discuss the potential impact of the single multi-target drug approach and drug discovery. Our main focus area will be on malaria, tuberculosis (TB), and other complex diseases such as diabetes and neurodegenerative diseases (NDs). We will also discuss alternative ideas to solve the current problems bearing in mind the fourth industrial revolution on drug discovery. Information in this review work was sourced from various databases such as google scholar and PubMed.

\section{Evolution of Drug Discovery}

For many decades, since the first century when the pioneers in science used medicinal plants as a source of the currently talked about therapeutic drugs (Figure 1), therapeutic drugs have been playing a crucial role in the treatment of both communicable and non-communicable diseases. However, the long-term success of various drug therapies is currently being threatened by the increasing prevalence of drug resistance. ${ }^{16,17}$ Since the isolation of

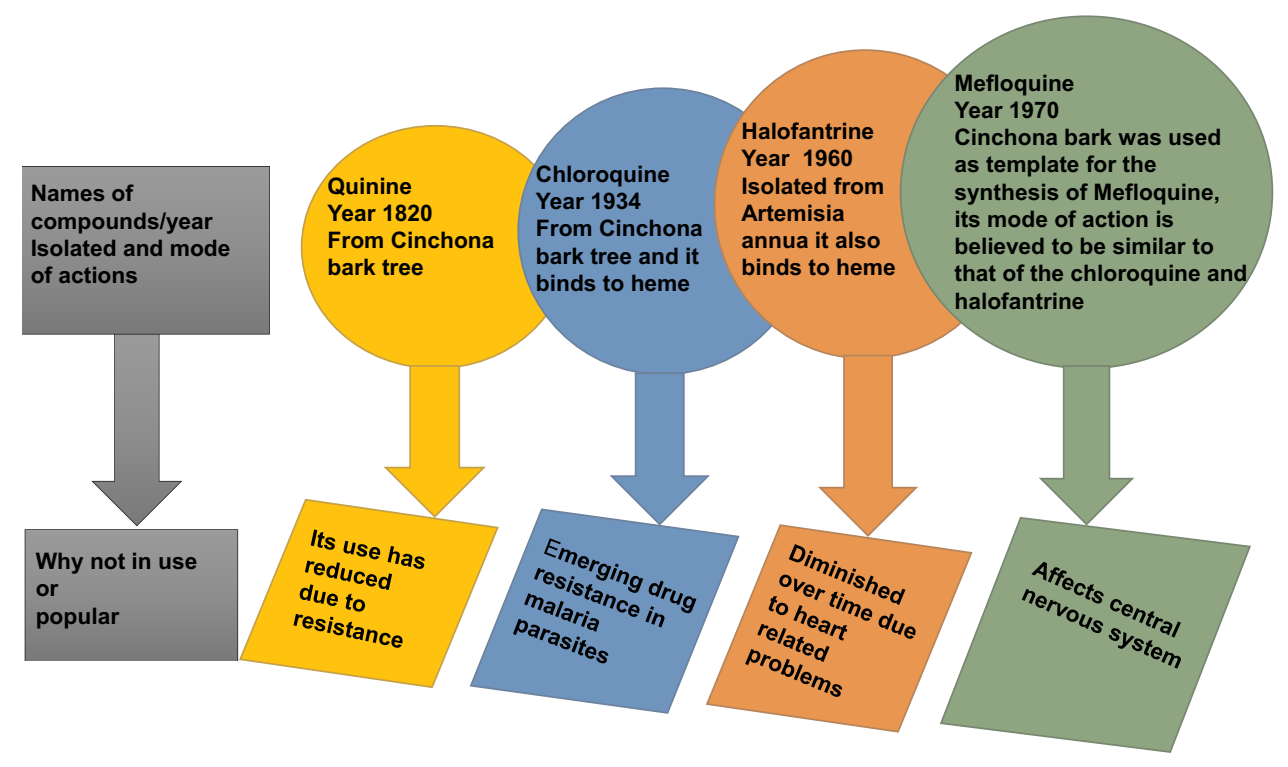

Figure I The discovery of anti-malaria drugs since 1820-1920s and their modes of action, and resistance. Most of these drugs depict the fact that their use and effectiveness had decreased dismally due to growing evidence of resistance and side effects. 
quinine from Cinchona bark tree, in 1820, the first chemically purified effective treatment for malaria, several other natural and synthetic compounds have been developed (Figure 1). Drug discovery and synthesis had been exploited based on the design for highly selective chemical entities to target a single biological entity. However, the single-target drugs commonly referred to as monotherapy has been faced with several challenges limiting their use. These include undesired side effects and increasing incidence of drug resistance, and limited efficacy against complex diseases in which the pathogenesis is dependent on a set of biochemical events and several bioreceptors operating concomitantly.

To overcome this burden of the so-called incurable diseases due to development of drug resistance, among other factors, the drug discovery and design platforms had to review and rethink of alternative approaches. This led to the introduction of polypharmacology as an alternative new therapeutic strategy. Polypharmacology refers to the use of therapeutic molecules, which are recognized by different biomolecular targets. ${ }^{18}$ The introduction of combination therapy from monotherapy seemed to be a promising approach to eradicate different chronic complex diseases. There is currently an increasing interest in single drugs capable of acting on multiple molecular targets. This latest strategy advocates the combination, in a single scaffold, of different structural subunits that allow the molecular recognition by more than one bioreceptor. $^{5-7}$ The transition towards a single multitarget drug therapy is timely and appropriate to fight against the complex life-threatening diseases.

\section{Multi-Target Drugs in Malaria}

The incidence rate of malaria declined globally between 2010 and 2017, from 72 to 59 cases per 1000 population at risk. Although this represents an $18 \%$ reduction over the period, the number of cases per 1000 population at risk has stood at 59 for the past 3 years. Most malaria cases in 2017 were in the WHO African Region (200 million or 92\%), followed by the WHO South-East Asia Region with $5 \%$ of the cases and the WHO Eastern Mediterranean Region with $2 \% .{ }^{19,20}$ The spread of multi-drug resistance in malaria treatment and the absence of new antimalarial compounds requires an urgent need for new drug regime for malaria, which kills 11 million people every year. ${ }^{19-22}$ There is a growing interest in drug combinations as an alternative new treatment approach against malarial parasite. Azithromycin is a macrolide antibiotic that is particularly attractive as an antimalarial because of its safety in children. In combination studies with quinine, azithromycin has demonstrated high efficacy in curing uncomplicated falciparum malaria, and recent prophylaxis trials suggest that azithromycin also has high efficacy for preventing Plasmodium vivax malaria. Combination therapy is widely accepted as the best approach to the management of $P$. falciparum malaria because it produces an excellent clinical response and slows the development of antimalarial drug resistance. Currently, artemisinin-based combination therapy (ACT) is recommended for the treatment of $P$. falciparum malaria. Fast-acting artemisininbased compounds are combined with a drug from a different class. Companion drugs include lumefantrine, mefloquine, amodiaquine, sulfadoxine/pyrimethamine, piperaquine and chlorproguanil/dapsone (Figure 2). Artemisinin derivatives include dihydroartemisinin, artesunate and artemether. A co-formulated drug is one in which two different drugs are combined in one tablet; this is important to ensure both drugs are used. The adverse effect profiles of the artemisinin-based combination treatments are determined by the partner drug. Most malaria-endemic countries have now adopted artemisininbased combination treatments as first-line treatment of falciparum malaria, but in most of these only a minority of the patients that need artemisinin-based combination treatments actually receive them. ${ }^{23}$ Most combination therapy failures are associated with inadequate dosage, because increasing dosage of azithromycin in combination with quinine leads to the high cure rates. ${ }^{24,25}$ Figure 2 presents some of the combination drugs that have been used against $P$. falciparum. In addition to the ATC, triple artimensine combination therapy has been reported in some areas where malaria continues to affect thousands of people. In this review, our focus is on ATCs, of which we have many combination therapies.

Polyamines such as spermidine, spermine and putrescine play an essential role in differentiation, proliferation and cell growth with S-Adenosylmethionine and Ornithine decarboxylase being the main role players in their biosynthesis. ${ }^{26}$ The structure and properties of polyamines have been extensively studied. Their polycationic nature makes them interact with various biomolecules such as DNA and other proteins, thus becoming ideal drug targets in malaria and cancer. On the other hand, polyamines are believed to be involved in the synthesis of heat shock proteins also known as molecular chaperones whose role is to prevent misfolding of newly synthesized proteins that 


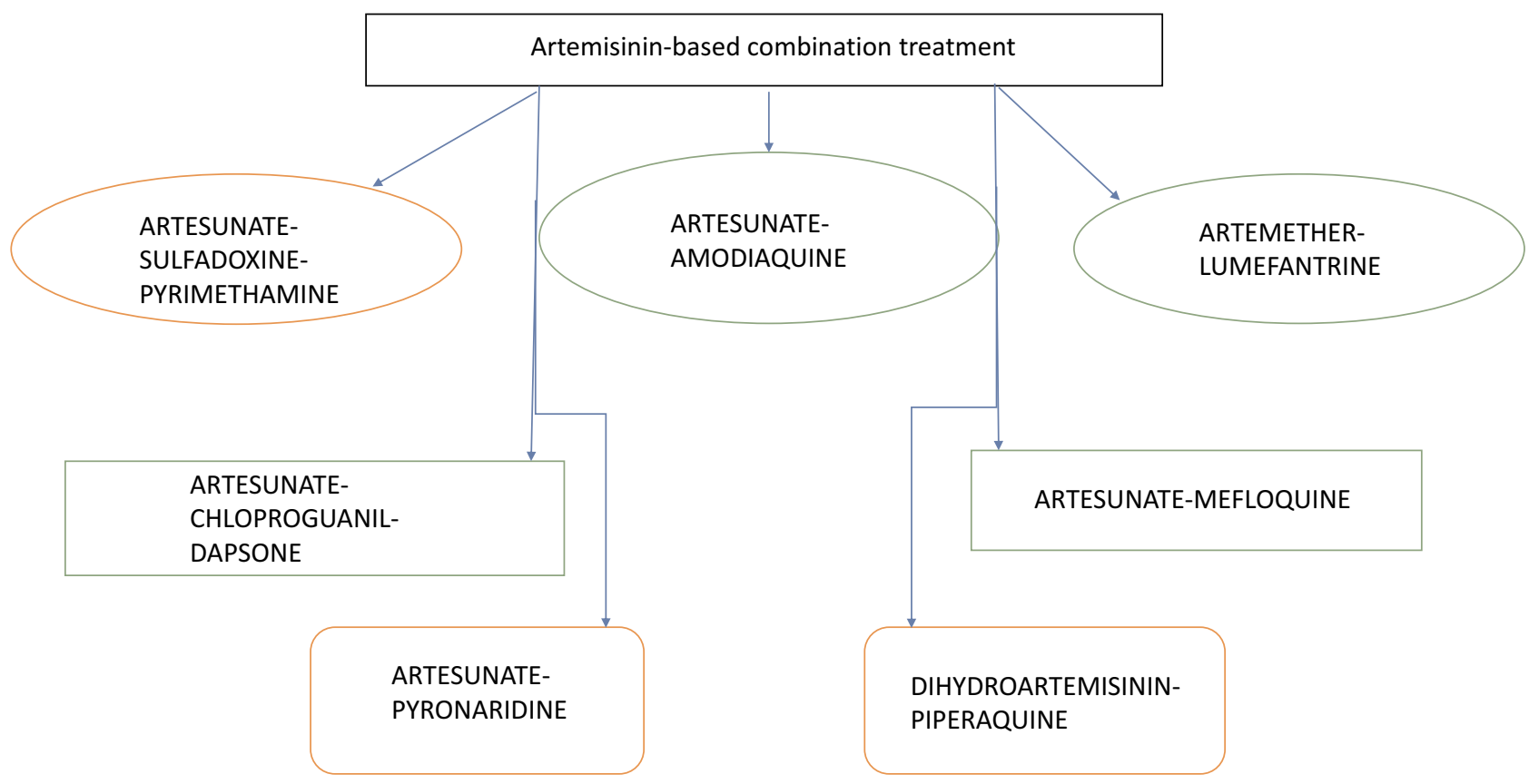

Figure 2 Selected artemisinin-based combination treatment against $P$. falciparum.

could lead to cell death. ${ }^{27-33}$ Both molecular chaperones and polyamines play a vital role in keeping cellular system in good shape; hence, they are regarded as drug targets. Understanding of the structure-activity relationship between ligands and molecular targets is crucial in drug design platforms. Therefore, targeting both polyamines and molecular chaperones in malarial parasite and cancer could prove to be a solution.

\section{Cancer Treatment}

According to Globcan (2012) reports, cancer kills more people than AIDS, tuberculosis, diabetes and malaria combined. ${ }^{20}$ Cancer has been, for years, the deadliest form of chronic disease, claiming millions of lives yearly, worldwide. For example, in the United States only, cancer has claimed 1 million lives in the year 2018, with Africa being the second-highest to be reported. ${ }^{34}$ The most popular drugs for cancer treatment include carboplatin, adriamycin and fluorouracil. Like in other complex diseases, the introduction of combination therapy from monotherapy seemed a positive approach in cancer treatment. The use of combination chemotherapy to treat cancer was inspired in the 1960s when scientists wondered whether the approach to treating tuberculosis using a combination of antibiotics to reduce the risk of resistance would work for the treatment of cancer as well. ${ }^{35}$ Using this approach, cancers that had previously been almost universally fatal such as acute lymphocytic leukaemia and Hodgkin's lymphoma became largely curable. Since that time, combination chemotherapy has been adopted for the treatment of many other cancers as well.

In the 1970s, combination chemotherapy was found to be more effective than single drugs for people with lung cancer, and more effective than "sequential chemotherapy" or using chemotherapy drugs one at a time in sequence, rather than at the same time. It is only in the last decade that chemotherapy has been added to a new type of immunotherapy called checkpoint inhibition therapy. The therapy targets vital regulators of the immune system that when stimulated can reduce the immune response to an immunologic stimulus. ${ }^{36}$ Checkpoint inhibitors work by blocking the receptors that cancer cells use to signal T-cells. In some situations, adding chemotherapy drugs appears to make immunotherapy drugs more effective. At the current time, combination chemotherapy may be more appropriate in some cases and with some cancers, while single-drug chemotherapy may be better in others. ${ }^{37}$ Although many types of cancers are initially susceptible to chemotherapy, over time they can develop resistance. While lack of selectivity has previously been considered a significant obstacle for anticancer drug discovery, scientists have recently embraced the design and discovery of more potent and efficacious anticancer drugs based on the multi-target approach strategy. ${ }^{38}$ 
Examples of some anticancer drugs with multi-target properties include lapatinib, which is a reversible, ATPcompetitive inhibitor of the human epidermal growth factor receptor 2 (HER2) and epidermal growth factor receptor (EGFR) tyrosine kinases and duvelisib, a novel oral dual inhibitor of PI3K- $\delta, \gamma .{ }^{39}$ Duvelisib is showing highly promising clinical efficacy in advanced hematologic malignancies. ${ }^{40}$ The recent new strategy for cancer treatment involves the design and synthesis of hybrid compounds as multi-targeted anticancer agents. Hybrid compounds having more than a single-target have been considered as more efficient and potent anticancer agents, since it is almost impossible to destroy cancer cells with a single target. ${ }^{41}$ Hybrid compounds overcome many disadvantages of single cancer drugs such as low solubility, adverse effects, and multidrug resistance.

\section{Mycobacterium Tuberculosis}

TB is an airborne infectious disease attributed to approximately 1.3 million deaths in 2017 alone. ${ }^{42,43}$ The etiology of most cases of the TB disease can be traced back to Mycobacterium tuberculosis. Lungs are the main line of attack by $M$. tuberculosis and symptoms are often presented as severe coughing, fever and chest pain. According to the WHO, TB alone is responsible for four deaths per minute and is recognized as the second leading global cause of death from a single infection. ${ }^{43,44}$ TB cases reported in 2017 are approximately 10 million, with more than half (5.8 million) cases being reported in men. ${ }^{43}$ Furthermore, in poverty-stricken developing countries, the lack of treatment often leads to the development of complicated TB, and many children with pulmonary TB present with, or develop complicated forms of other chronic lung diseases. The current first-line drug treatment against tuberculosis has various limitations, such as efficiency towards complicated TB cases, drug relates side-effects and lengthy drug therapy (6 to 12 months). ${ }^{45}$

Furthermore, the treatment of TB is complicated by the rampant development and spread of antibiotic resistance, especially multi-drug resistance-TB (MDR-TB) and extensively drug resistance (XDR-TB) M. tuberculosis. ${ }^{42}$ Both MDR-TB and XDR-TB are a major threat to the efficacy of the first and second lines of antibiotic treatment of $M$. tuberculosis infections. The first-line cocktail drugs used in the treatment of TB infections, include isoniazid and rifampicin, which are usually supplemented with pyrazinamide and ethambutol in the first 2 months. ${ }^{46}$ The WHO estimates that there were 600 000 new cases with resistance towards first-line drugs. ${ }^{43,47}$ Furthermore, 490000 of these cases were MDR-TB positive.
Among HIV-positive patients, TB has been reported to be responsible for the highest mortalities, with over $40 \%$ of HIV deaths being linked to M. tuberculosis. ${ }^{48}$ Most TB infections are latent with the potential for reactivation and approximately a third of the world's population has latent $M$. tuberculosis infection. ${ }^{49}$ The ever-growing threat of drug resistance has elevated the need for new interventions and forced the introduction of more costly drug combinations. ${ }^{42,45,47}$

\section{Multi-Targeting Potential of Natural Products in Tuberculosis Treatment}

Medicinal plants have traditionally been used in the treatment of pulmonary diseases such as TB, yet most of these have not been fully elucidated. ${ }^{50}$ Furthermore, most of the plant species or compounds have not been explicitly tested against TB essential proteins, or protein biomarkers contributing to TB latency. ${ }^{51}$ This knowledge may find application in developing new anti-TB drugs. Medicinal plants have been shown to harbour a wide diversity of chemical structures, displaying a wide range of potency towards M. tuberculosis specificity. ${ }^{52-55}$ Plant-derived compounds with low toxicity and high activity towards $M$. tuberculosis have previously been identified against $M$. tuberculosis species and these should be tested in combination with the current first-line drugs. In the last decade, 25 newly approved drugs were derived from natural products, with 31 additional drugs either at or past Phase III clinical trials. In the past decade a number of researchers have reported extracts from edible plants such as aromatic ginger, roselle, celebes pepper and banana leaves as potent MDR-TB inhibitors. ${ }^{54,56,57}$

Examples of some antitubercular drugs with multitarget properties include SQ109 and its derivatives, which have been reported to inhibit MmpL3 and MmpL11, transporter proteins involved in cell wall biosynthesis, and MenA and MenG, involved in menaquinone biosynthesis. ${ }^{58}$ Furthermore, Li and colleagues (2014) demonstrated the inhibitory capabilities of the SQ109 derivatives against a panel of various Gram-positive and Gram-negative bacteria, including the M. tuberculosis, fungi and the $P$. falciparum parasite. ${ }^{58-60}$

\section{Mycobacterium Tuberculosis Drug Development and Phage-Based Therapy: Potential Anti-TB Treatment}

The discovery of new drugs towards most infectious diseases such as TB have undoubtedly been a slow and daunting 
process. However, the recent Food and Drug Administration (US) approval of pretomanid represents the third anti-TB drug in 50 years. The triple combination of bedaquiline, pretomanid and linezolid has been reported as a potential "game-changer" with high efficacy towards extensively drug-resistant $\mathrm{TB}^{61}$ This multi-drug target regimen has been reported to inhibit mycobacterial ATP synthase, mycolic acid synthesis and energy production. ${ }^{62}$ In 2015, the discovery of a potent anti-TB drug, TB47, a pyrazolo[1,5a]pyridine-3-carboxamide, sparked new hope in the fight against TB. ${ }^{63}$ The compound, TB47, was shown to be effective against 37 MDR-TB clinical strains. ${ }^{64}$ Furthermore, this compound was shown to be highly antimycobacterial, inhibiting the growth of M. bovis, M. ulcerans, M. marinum, $M$. smegmatis and $M$. abscessus at very low concentrations, $\geq 0.008 \mu \mathrm{g} / \mathrm{mL}$ of TB47 displayed potent bactericidal activity in comparison to rifampicin $(0.2 \mu \mathrm{g} / \mathrm{mL}) .{ }^{63,64}$ Liu and coworkers (2019) recently demonstrated that TB47 directly interacts with the respiratory cytochrome bcc Complex and is a potential antitubercular agent that synergistically inhibits M. tuberculosis growth in the presence of other first-line drugs. TB47 also inhibited the growth of yeast infection (Candida albicans) and some of ESKAPE superbugs (Enterococcus faecium, Staphylococcus aureus, Klebsiella pneumoniae, Acinetobacter baumannii, Pseudomonas aeruginosa and Escherichia coli) ${ }^{64,65}$ The inclusion of TB47 or its derivatives to the current drug regimen may have desirable outcomes in the pursuit of multi-target approaches of various complex diseases. ${ }^{65,66}$

Bacteriophages or phages are viruses that infect and lyse specific bacterial cells. ${ }^{67}$ Phage-treatment against bacterial infections was first used in the early 1920s; however, subsequently lost favour due to the discovery of antibiotics. Phage lytic enzymes (also referred to as endolysins or lysins), a class of phage-encoded proteins, are highly attractive to treat antibiotic-resistant bacteria because of their extraordinary bacterial target specificity. ${ }^{68-70}$ They are widely studied for their potential as an alternative to antibiotics or to enhance the effectiveness of antibiotics. ${ }^{71-74}$ Other studies have suggested the development of a combined "endolysins-antibiotic" regimen. ${ }^{75,76}$ Schuch and co-workers demonstrated that the combined use of endolysin CF-301 and antibiotics potentiates their combined antibacterial activity for treating methicillin-resistant staphylococcus. ${ }^{71}$ The combined use of endolysin CF-301 with vancomycin or daptomycin resulted in the increased survival rate of staphylococcal-infected mice compared to the use of antibiotics alone. ${ }^{71,73}$ Mycobacteriophage derived protein, SWU1 gp39, increases cell wall permeability of M. smegmatis and heightened the efficacy of various antibiotics, such as erythromycin and ampicillin. ${ }^{77}$ Phagetherapy is the therapeutic use of lytic bacteriophages to treat pathogenic bacterial infections. Although phagetreatment is not widely accepted, phage-therapy centres such as the one based in Georgia are providing phagebased treatment solutions to various patients infected with multi-drug resistant superbugs, including the ESKAPE pathogens. According to Dedrick and co-authors, bioengineered phages were recently used to successfully treat a 15-year-old patient infected with a drug-resistant Mycobacterium abscessus. ${ }^{78}$ The case report states that an intravenous three-phage cocktail treatment was used and yielded visible clearing of the infected skin, wound closure and improved liver function. ${ }^{78,79}$ Thus, combination therapy of current drug regimens with bacteriophage/bacteriophagederived proteins may be more effective in comparison with the current treatment.

\section{Trends in Antidiabetic Drugs Discovery}

Diabetes mellitus, a complex metabolic disease characterized by chronic hyperglycemia, has become a global health concern rapidly reaching epidemic levels. ${ }^{80,81}$ Persistent hyperglycemia observed in diabetic patients is responsible for the various debilitating effects of diabetes. Among the different types of diabetes, type 2 diabetes (characterized by cellular insulin resistance) is the most common and account for the highest number of diabetes cases. ${ }^{82}$ There is a globally agreed target to halt the rise in diabetes and obesity by $2025{ }^{83,84}$ Over the years, we have witnessed a great progress in the discovery and development of antihyperglycemic drugs to manage diabetes. This progress could be attributed, in part, to a continually increasing understanding of the disease nature. Diabetes is not only caused by malfunction or dysregulation of a single protein and/or pathway, but rather an array of multiple biochemical processes. These include deficiency in insulin secretion, disturbances in insulin signalling system in the major insulin target organs and eventual disturbance in glucose and lipid metabolism. ${ }^{3,4,85}$ Due to the complexity of diabetes, a search for its absolute treatment is ongoing.

\section{Current Antidiabetic Therapy}

Since glycemic control has been the main focus in diabetes management, insulin injection has, over the years, been the main form of diabetes management. Despite the efficacy of insulin therapy, it has, however, been associated with 
a significant risk of hypoglycemia and weight gain. ${ }^{86,87}$ Moreover, owing to the increasing prevalence of type 2 diabetes (T2D), commonly characterized by insulin resistance, various oral hypoglycemic drugs were introduced. These came in the form of insulin sensitizers (biguanides, thiazolidinediones, TZD) and secretagogues (sulfonylureas, meglitinide) as well as $\alpha$-glucosidase inhibitors, which have no direct effect on insulin action but only limiting glucose intestinal absorption. ${ }^{5}$

In recent years, other single-target antidiabetic drugs such as dipeptidyl peptidase-IV (DPP-IV), and sodiumglucose co-transporter-2 (SGLT2) inhibitors have been approved for treatment of T2D. ${ }^{5}$ DPP-IV degrades and inactivates incretions (glucagon-like peptide-1, glucose inhibitory polypeptide), resulting in loss of their insulinotropic effect. ${ }^{62}$ SGLT-2 inhibitors, unlike other antidiabetic drugs, work by inhibiting the renal SGLT-2 protein (responsible for $80-90 \%$ of glucose reabsorption), resulting in increased glucose excretion in the urine. ${ }^{34}$

In a continuous fight against diabetes, following the advent of the latest antidiabetic drugs such as DPP-IV and SGLT2 inhibitors, various combination therapies have been introduced and utilized. These include dual (Metformin and sulfonylurea or metformin and DPP-IV inhibitor), triple (metformin, TZD and DPP-IV inhibitor) and even quadruple (metformin, TZD, DPP-IV and SGLT2 inhibitors) combination therapies. Despite all the great progress made thus far in drug development for diabetes management, the clinical limitations of the current antidiabetic drugs, either as monotherapy or in combinations, are an evidence of the need for novel drugs that can satisfactorily halt diabetes and its complications. Considering the multifaceted nature of diabetes, discovery and development of multi-target drug regime, rather than singletarget drugs, may prove to be the best approach towards winning the battle against the disease. ${ }^{4}$

\section{Towards Multi-Targeted Oral Antidiabetic Drugs}

The concept of developing multi-target drugs against complex diseases such as diabetes is fast growing in drug discovery. In making efforts towards the new paradigm of multi-target antidiabetic drugs, few compounds such as sotagliflozin and imeglimin (Figure 3) have already been reported to show promising results, giving hope to diabetic patients.

\section{Sotagliflozin}

Sotagliflozin, first in a new class of antidiabetic agents, works by inhibiting both SGLT1 and SGLT2 and thus diminishing intestinal glucose absorption as well as renal glucose reabsorption. ${ }^{6}$ This drug is aimed at treating both type 1 diabetes (T1D) and T2D either as monotherapy or add-on therapy to other antidiabetic agents. ${ }^{85}$ Even though this drug has been associated with increased risk of diabetic ketoacidosis, diarrhoea and genital tract infections, ${ }^{7}$ its dual effect gives it an advantage over the selective SGLT2 inhibitors. Reports show that sotagliflozin has completed Phase 3 clinical trials for T1D, and it is yet to complete phase 3 trials for T2D treatment. ${ }^{7}$ However, the European Medicines Agency (EMA) recently announced the approval of sotagliflozin, in the European Union, as an adjunct to insulin therapy for type 1 diabetics.

\section{Imeglimin}

Imeglimin is also the first candidate in the new class (glimins) of oral antihyperglycemic drugs. Unique about this compound is its ability to act on the three key organs, liver, muscle, and pancreas, in the pathophysiology of T2D. ${ }^{8}$ The mechanism of imeglimin is linked to its modulation of mitochondrial bioenergetics in these key organs, stimulating insulin secretion in response to glucose and improving insulin sensitivity while inhibiting hepatic gluconeogenesis. ${ }^{9}$ In addition to its antihyperglycemic
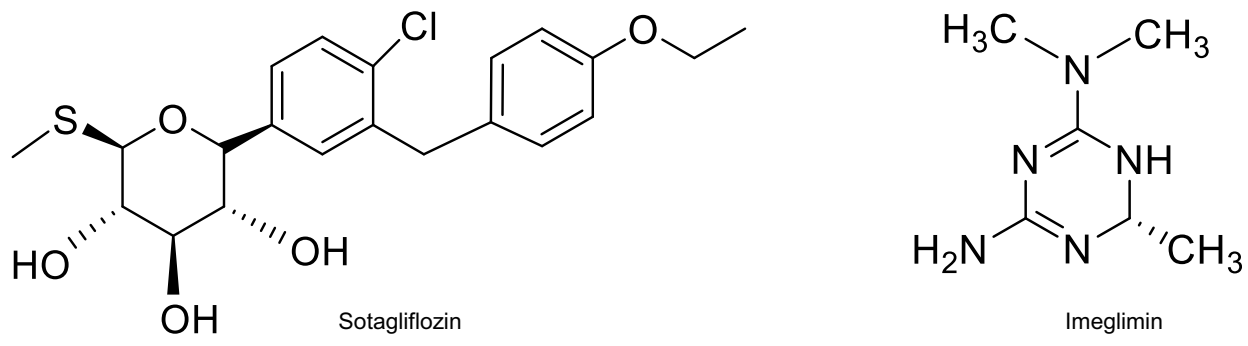

Figure 3 Chemical structures of imeglimin and sotagliflozin. 
effect, this compound has also been reported to protect against pancreatic beta-cell apoptosis ${ }^{8}$ and oxidative damage crucial for the prevention of micro- and macrovascular damage of diabetes. ${ }^{10}$

\section{Natural Products as Potential Sources of Multi-Target Antidiabetic Drugs}

In addition to the established link between hyperglycemia and hyperlipidemia in the diabetic state, hyperglycemiainduced oxidative stress is further reported to stimulate several glucose metabolic pathways that are associated with diabetic complications. Therefore, it is essential to also consider the antioxidant and anti-inflammatory properties of compounds when designing or searching for new antidiabetic drugs. Several plant-derived pure compounds have been reported to exhibit glycemic control with different mechanisms of action, suitable for the multi-target approach. ${ }^{11,12}$ In vitro and in vivo models of diabetes studies have shown some of the plant-derived compounds such as ginsenoside $\mathrm{Rb} 1,{ }^{13-15,88}$ methyl-3 $\beta$-hydroxylanosta-9,24dien-21-oate (RA-3) ${ }^{89-92}$ and mangiferin ${ }^{93,94}$ (Figure 4) to have a promising potential multi-target effect against diabetes (Table 1). Even though natural products' level of bioavailability, efficacy and specificity on binding to targets is still debatable, with the help of some computational chemistry, these potential hindering challenges could be overcome. The plant-derived lead molecules could be used either directly or as structural templates for the development of more effective multi-target antidiabetic drugs.

\section{Where are We Today}

During the last years, medicinal chemistry has searched for new tools and alternatives capable of reaching more agility, security and a more efficient direction in the design and prospection of drug candidates. In this context, strategies of drug discovery focusing on the development of ligands that act selectively on specific targets have been re-discussed, since they have limited adoption in multifactorial diseases. It is undeniable that this strategy has had over the time countless success for the Pharma Industry and the treatment of diseases, paving the current stage of evolution in therapeutics. ${ }^{82,95-103}$ The need to overcome such limitations in efficacy and therapeutic security has supporting changes in the current so-called reductionist paradigm of "one targetone drug" (Figure 5). The search for better results in clinical practices, as a consequence of lack in efficiency of some treatments based on single drugs and market decisions, has led to the development of the concept of polypharmacology as a new therapeutic strategy. The latest strategy advocates the combination in a single scaffold of different structural subunits that allow the molecular recognition by more than one bioreceptors, acting in a simultaneous mode in multiple targets interconnected to biochemical networks, responsible for the pathophysiology of multifactorial diseases. ${ }^{5-7}$

Appreciation of the polypharmacology concepts could be exemplified by the 86 new drugs with multi-targets, approved by the FDA in USA among 462 new molecular entities (NMEs) in the period from 2000 to $2017 .^{2,104}$ This approach, considering multifunctional drugs (MTDs) or multi-target directed ligands (MTDLs) associated with

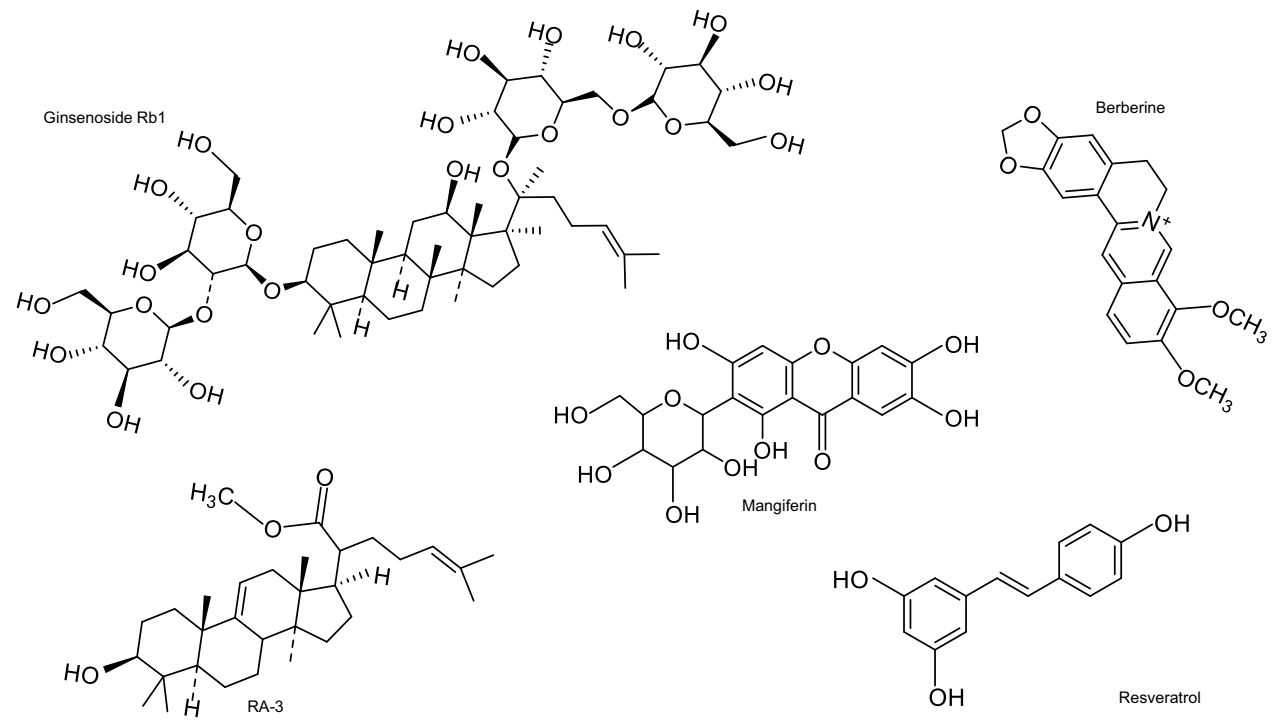

Figure 4 Chemical structures of some of the plant-derived compounds with promising potential multi-target effect against diabetes. 
Table I Some of the Plant-Derived Compounds with Promising Potential Multi-Target Effect Against Diabetes

\begin{tabular}{|l|l|l|l|}
\hline Plant & $\begin{array}{l}\text { Active } \\
\text { Compound }\end{array}$ & Reported Effects/Mechanisms & Reference \\
\hline $\begin{array}{l}\text { Berberis } \\
\text { vulgaris }\end{array}$ & Berberine & $\downarrow$ Blood glucose; $\downarrow$ G6P activity; $\uparrow$ Insulin sensitivity; $\uparrow \beta$ cells protection; $\downarrow$ Gluconeogenesis & 15 \\
\hline $\begin{array}{l}\text { Panax } \\
\text { notoginseng }\end{array}$ & $\begin{array}{l}\text { Ginsenoside- } \\
\text { Rbl }\end{array}$ & $\begin{array}{l}\downarrow \text { Blood glucose; } \downarrow \text { Adipocyte lipolysis; } \uparrow \text { Insulin sensitivity; } \uparrow \text { GLP-I secretion; } \uparrow \text { Islet } \beta \text {-cells } \\
\text { protection }\end{array}$ & $13-15,88$ \\
\hline $\begin{array}{l}\text { Protorhus } \\
\text { longifolia }\end{array}$ & RA-3 & $\begin{array}{l}\downarrow \text { Blood glucose; } \downarrow \text { G6P; } \uparrow \text { Insulin sensitivity; } \downarrow \text { IL-6; } \downarrow \text { Blood lipids [TG, TC, LDL]; } \uparrow \text { HDL; } \uparrow \text { Islet } \beta \text {-cells } \\
\text { protection; } \uparrow \text { Antioxidant status }\end{array}$ & $74-76$ \\
\hline $\begin{array}{l}\text { Mangifera } \\
\text { indica }\end{array}$ & Mangiferin & $\begin{array}{l}\downarrow \text { Blood glucose; } \uparrow \text { HK \& } \uparrow \text { GK; } \downarrow \text { G6P; } \uparrow \text { Insulin, sensitivity; } \downarrow \text { Blood lipids [TG, TC, LDL]; } \uparrow \text { HDL; } \uparrow \\
\text { Glycogenesis; } \uparrow \text { Antioxidant status; } \downarrow \alpha \text {-Glucosidase; } \downarrow \text { NF- } k \beta\end{array}$ & 78,79 \\
\hline Vitis vinifera & Resveratrol & $\begin{array}{l}\downarrow \text { Blood glucose; } \downarrow \alpha \text {-amylase and } \alpha \text {-glucosidase; } \downarrow \text { Gluconeogenesis; } \uparrow \beta \text {-cell function and insulin } \\
\text { action; } \uparrow \text { Antioxidant status }\end{array}$ & 3 \\
\hline
\end{tabular}

Notes: $\uparrow$ - increase/activate; $\downarrow$ - decrease/inhibit.

Abbreviations: HK, hexokinase; GK, glucokinase; G6P, glucose-6-phosphatase; TG, triglycerides; TC, total cholesterol; LDL, low density lipoprotein; VLDL, very low density lipoproteins; HDL, high density lipoprotein; IL-6, interleukin-6; NF-k $\beta$, nuclear factor kappa beta.

the same disease (symbiotic drugs), ${ }^{105}$ has been gaining space and especial attention, changing the conception in drug design of new drug candidates for several diseases, with a special highlight for neurodegenerative diseases, such as Alzheimer's (AD) and Parkinson's diseases (PD). Taking $\mathrm{AD}$ and $\mathrm{PD}$ as representative multifactorial diseases, despite these pathologies being distinct, they retain common characteristics such as a series of biochemical and physiological cascade events directly or indirectly associated with essential oxidative stress and inflammatory process. $^{95-97,99-102,106-112}$

Although the pharmaceutical industry aggressively markets anticholinergic drugs for the treatment of $\mathrm{AD}$, these drugs have shown only marginal and transient effects, with no curative properties and only a moderate ability to restrain neurodegeneration progress. In spite of substantial investments made by the industry in search of new drugs, the truth is that progress toward innovative, small-molecule therapies for neurodegenerative diseases has been very modest. ${ }^{113}$ In the words of Lansbury

if asked on a group of academic or pharmaceutical scientists why there are no effective drugs for $\mathrm{AD}$, they would probably respond that the underlying etiology of $\mathrm{AD}$ is not understood at the level that is required for drug discovery. Although continued investigations of the pathogenic pathways and potential therapeutic targets are important, the lack of this information does not justify the lack of progress toward a drug. ${ }^{113}$
The history of drug discovery is witness of how the lack of knowledge about a specific molecular target or etiology of a disease, is not impeditive for the discovery and development of drugs in almost all therapeutical classes. Conversely, during the twenty years of research about $\mathrm{AD}$ and $\mathrm{PD}$, literature offered several high-profile publications supporting the "amyloid hypothesis" and "dopamine-based strategies", respectively, as the correct ways to discover effective alternatives for the management of $\mathrm{AD}$ and PD. However, most of these theories failing to lead to any drug candidates outside academia. For industry, it appears that controversy around an issue is a reflection of a lack in knowledge about pathogenesis, and could be used as an argument for low interest or insecurity in investments. $82,106,112,114-117$

Perhaps, the widespread attitude that target-driven drug discovery is the only or even the most successful pathway to new drugs, has created an obstacle to progress against neurodegenerative diseases. ${ }^{105}$ In the case of neurodegenerative diseases, like $\mathrm{AD}$ and $\mathrm{PD}$, with a very complex pathogenesis, the reductionist philosophy may not be the way to reach novelty and effectiveness in drug discovery. ${ }^{107}$ In the last decade, advances in molecular biology, biochemistry and neuroscience have led to a remarkable change in the knowledge about the etiology and pathophysiology of NDs, especially for AD. In such pathologies, a multitude of physiological changes are present, including aberrant protein folding, protein degradation pathways, mitochondrial dysfunction, imbalanced 


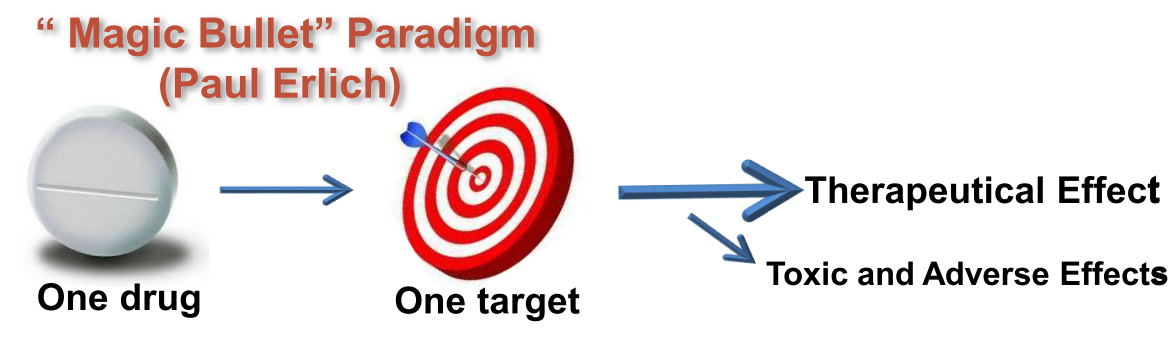

Polypharmacology: "One Disease - Multiple Targets"

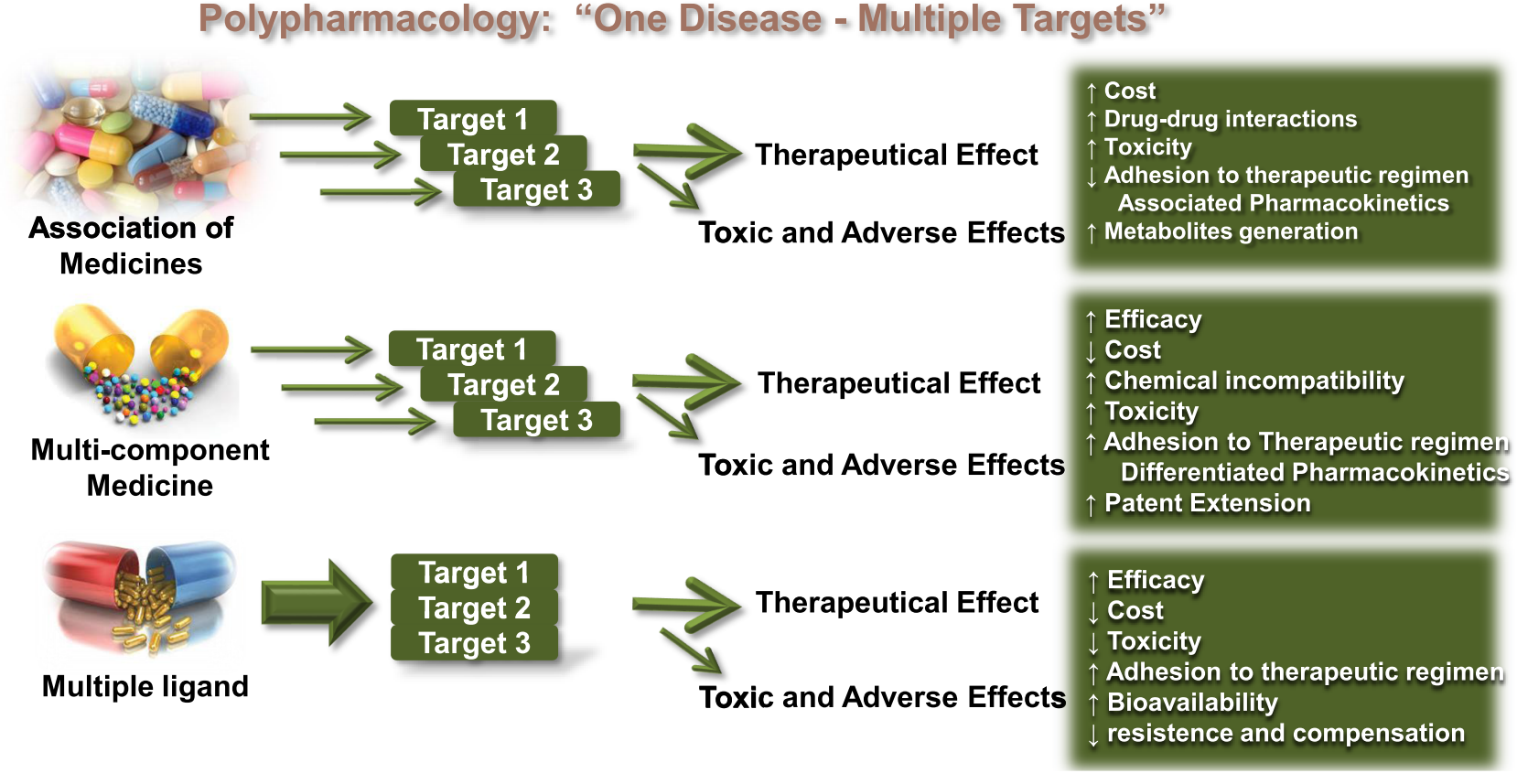

Figure 5 Conceptual aspects of the reductionist approach (“Magic Bullet”) and polypharmacology.

energy production, compromised axonal transport processes, uncontrolled production of oxygen and nitrogen radical species, inflammation signaling, and ultimately induced cell death. ${ }^{102,108,109,118-120}$ In a non-physiological condition, abnormal accumulation senile plaques constituted by aggregates of toxic insoluble $A \beta$ oligomers is due to an imbalance between the levels of $A \beta$ production and clearance. Consequently, $\mathrm{A} \beta$ oligomers are overproduced and lead to synaptic damage by forming pore-like structures with channel activity, which can modify glutamate receptors and culminate in excitotoxicity.

Additionally, these deleterious conditions induce circuitry hyperexcitability, mitochondrial dysfunction, lysosomal failure, and alterations in signaling pathways involved in synaptic plasticity, neuronal cells, and neurogenesis. ${ }^{121}$ On the other side, Tau is a soluble protein, abundant in almost all nucleated cells, with the function of stabilizing microtubules, playing a dominant role in axonal growth and neuronal development. Under AD conditions, upregulation of kinases and downregulation of phosphatases result in an abnormal hyperphosphorylation of Tau protein that generates double helical insoluble filaments and tangled structures known as neurofibrillary tangles (NFT), which lead to neuronal degeneration and synaptic dysfunction. NFTs are originally formed inside the neuron, and after its death, these structures are released to the extracellular environment and are engulfed by astrocytes and microglia cells. ${ }^{122}$ The literature is rich in data supporting that inflammation around senile plaques destroys neighboring neurons, as well as intracellular neurofibrils, and is responsible for oxidative stress with an increase of radical species that in turn, modify the intracellular environment contributing for neuroinflammation. ${ }^{108,114}$ Chronic inflammation is related to the activation of microglia, the most abundant of the resident immune cells in the brain, as a consequence of an injury to the brain tissue. Once activated, microglia produce pro-inflammatory and neurotoxic factors including cytokines such as TNF- $\alpha$, interleukin-1 beta (IL-1 $\beta$ ), IL-6, and free radicals (eg, NO, superoxide), 
which contribute to neuron damage, exacerbate tau pathology and contribute for chronic inflammation and the progression of neurodegeneration. ${ }^{120,123}$

Oxidative stress (OS) has been also recognized as an important factor in NDs pathogenesis, as it is a consequence of the incapability of the natural antioxidant defense system to counteract the excessive formation of reactive oxygen or nitrogen species produced by a living organism during the biochemical changes implicated in cell metabolism. In the context of $\mathrm{AD}$, literature data from the last twenty years evince that nine molecular targets have been mostly exploited in the search for novel disease-modifying drug candidates for $\mathrm{AD}$, including AChE, BACE-1, oxidative enzymes, biometals (eg, $\mathrm{Fe}^{2+}, \mathrm{Cu}^{2+}$ and $\mathrm{Zn}^{2+}$ ), glutamate receptors (eg, NMDA), serotonin receptors (5-HTRs), histamine receptors $\left(\mathrm{H}_{3}\right)$ and phosphodiesterases. In addition, oxidative stress, mitochondrial dysfunction and neuroinflammation, along with astrocyte and microglial activation have been extensively considered in drug discovery strategies. In fact, deregulation of the redox-state actively contributes to neurodegeneration and triggers several cellular events and pathways which also contribute to the progression of $\mathrm{AD}$ and PD. ${ }^{115,124,125}$

The epigenetic hypothesis is another recent therapeutic approach for the treatment of NDs. By this perspective, DNA modifications due to methylation and histone acetylation reactions, regulating gene expression at the transcriptional level, play a crucial role in $\mathrm{AD}$ and $\mathrm{PD}$ pathogenesis. For all aspects discussed above, including particular neurotransmitter receptors (eg, dopamine, serotonin, histamine, nicotine, and muscarine) and specific enzymes (eg, PDE, AChE, BuChE, MAO), AD and PD are now recognized as neurodegenerative disorders with high complex pathogenesis, with a multitude of biochemical and cellular events operating in an interconnected network. ${ }^{114,123}$ These particular pathophysiological features of such NDs, similar to other multifactorial diseases such as diabetes, cancer, chronic inflammation, and hypertension have led to an apparent consensus in the scientific community that it is time to change the way of thinking about drug discovery in order to reach better therapeutic results. Therefore, different from the medicinal chemistry and pharmacological strategies practiced to date, the design of highly potent and selective ligands as drug candidates have proven not to be the most effective and adequate approach to modulate molecular targets involved in this kind of pathology.
To combat diseases focusing on more than one molecular target or seeking the modulation of more than one disease-related effect is not a new concept. Indeed, combination therapy or polypharmacology indicates this strategy as a way to control more than one symptom or disturbance related to one pathology. In the last decade, scientific community seems to have recognized the importance of considering multiple ligand design as a new window for drug discovery. In fact, there is an increasing number of publications reporting different rational strategies for design of ligands aiming to concomitantly modulate more than one molecular target or biochemical pathway. These novel chemical entities will be useful for the treatment of NDs and other multifactor associated chronic diseases. ${ }^{4,12,37,96,97,99,100,102,103,106,110-113,120,123}$ This current and constant changing scenario is an undoubtable witness of the effort of medicinal chemists in the direction of the discovery of new disease-modifying drug candidates based on the concomitant modulation of a number of selected molecular targets as a current and more rational approach to overcome the therapeutic limitations observed up to date for the single-target directed drugs.

\section{What Future Holds for the Multi-Target Drug Search?}

Since the discovery of monotherapy treatment for various complex diseases, the approach has been constantly changing from mono-triple therapy due to resistance and side effects. Multi-target drug treatment approach holds a bright future when the monotherapy seems to be failing. The polypharmacology concept is also being well accepted and embraced by the pharmaceutical companies and researchers with focus being on development of multitarget drugs. Scientific reports have shown that with the multi-target drug approach in disease treatment, the issue of resistance could be a thing of the past. The starting point is screening protein networks through computational approach, in order to establish interacting proteins. This gives an idea of the proteins that can be vital role players on the parasite, bacterial or fungal survival in case of communicable diseases. Since these proteins interact during harsh conditions or when the parasite for example $P$. falciparum invades the host, thus produces a large amount of these crucial proteins for its survival. In most cases, these proteins interact directly or indirectly; hence, targeting them requires an in-depth knowledge of their 
structural and their activities. Based on this information, compounds with multi-targeting properties can be designed. Therefore, the search for multi-targeting drugs will continue and is probably our last hope in coming up with an effective treatment to eradicate complex diseases.

\section{Acknowledgments}

XHM acknowledged the University of Pretoria Research Development Program, CVJ is grateful to CNPq (\#310082/ 2016-1, \# 406739/2018-8) and FAPEMIG (\#CEX - APQ00518-17) for fellowship and financial support. FPDV is grateful to Coordenação de Aperfeiçoamento de Pessoal de Nível Superior - Brazil (CAPES) - Finance Code 001 for fellowship. OJP acknowledges the South African National Research Foundation (Grant Unique Number: 117775). The authors are also grateful to the SA-NRF for the financial support (Grant number: 121928) awarded to RAM.

\section{Disclosure}

The authors declare that they have no competing interests.

\section{References}

1. Medina-Franco JL, Giulianotti MA, Welmaker GS, Houghten RA. Shifting from the single to the multitarget paradigm in drug discovery. Drug Discov Today. 2013;18(9-10):495-501. doi:10.1016/ j.drudis.2013.01.008

2. Ramsay RR, Popovic-Nikolic MR, Nikolic K, Uliassi E, Bolognesi ML. A perspective on multi-target drug discovery and design for complex diseases. Clin Transl Med. 2018;7(1). doi:10.1186/s40169-017-0181-2

3. Brasnyó P, Molnár GA, Mohás M, et al. Resveratrol improves insulin sensitivity, reduces oxidative stress and activates the Akt pathway in type 2 diabetic patients. Br J Nutr. 2011;106(3):383-389. doi:10.1017/ S0007114511000316

4. Colín-Lozano B, Estrada-Soto S, Chávez-Silva F, et al. Design, synthesis and in combo antidiabetic bioevaluation of multitarget phenylpropanoic acids. Molecules. 2018;23(2):1-16. doi:10.3390/ molecules 23020340

5. Qaseem A, Barry MJ, Humphrey LL, et al. Oral pharmacologic treatment of type 2 diabetes mellitus: a clinical practice guideline update from the American College of Physicians. Ann Intern Med. 2017;166 (4):279-290. doi:10.7326/M16-1860

6. Garber AJ, Abrahamson MJ, Barzilay JI, et al. American Association of Clinical Endocrinologists' comprehensive diabetes management algorithm 2013 consensus statement - executive summary. Endocr Pract. 2013;19(3):536-557. doi:10.4158/EP13176.CS

7. Hussein Z, Wentworth JM, Nankervis AJ, Proietto J, Colman PG. Effectiveness and side effects of thiazolidinediones for type 2 diabetes: real-life experience from a tertiary hospital. Med J Aust. 2004;181 (10):536-539. doi:10.5694/j.1326-5377.2004.tb06441.x

8. Fouqueray $\mathrm{P}$, Leverve $\mathrm{X}$, Fontaine $\mathrm{E}$, Baquié M, Wollheim C. Imeglimin - a new oral anti-diabetic that targets the three key defects of type 2 diabetes. J Diabetes Metab. 2011;02(4). doi:10.4172/21556156.1000126

9. Vuylsteke V, Chastain LM, Maggu GA, Brown C. Imeglimin: a potential new multi-target drug for type 2 diabetes. Drugs $R D$. 2015;15(3):227-232. doi:10.1007/s40268-015-0099-3
10. Detaille D, Vial G, Borel A-L, et al. Imeglimin prevents human endothelial cell death by inhibiting mitochondrial permeability transition without inhibiting mitochondrial respiration. Cell Death Discov. 2016;2(1). doi:10.1038/cddiscovery.2015.72

11. Munhoz ACM, Frode TS. Isolated compounds from natural products with potential antidiabetic activity - a systematic review. Curr Diabetes Rev. 2017;14.(1). doi:10.2174/1573399813666170505120621

12. Li J, Yu H, Wang S, et al. Natural products, an important resource for discovery of $<$ br $>$ multitarget drugs and functional food for regulation of hepatic glucose metabolism. Drug Des Devel Ther. 2018;12:121-135. doi:10.2147/DDDT.S151860

13. Msomi NZ, Shode FO, Pooe OJ, Mazibuko-Mbeje S, Simelane MBC. Iso-mukaadial acetate from warburgia salutaris enhances glucose uptake in the 16 rat myoblast cell line. Biomolecules. 2019;9(10):10. doi:10.3390/biom9100520

14. Liu C, Zhang M, Hu M, et al. Increased glucagon-like peptide-1 secretion may be involved in antidiabetic effects of ginsenosides. J Endocrinol. 2013;217(2):185-196. doi:10.1530/JOE-12-0502

15. Zhou P, Xie W, He S, et al. Ginsenoside Rb1 as an anti-diabetic agent and its underlying mechanism analysis. Cells. 2019;8(3):204. doi:10.3390/cells 8030204

16. Olson S, English RA, Guenther RS, Claiborne AB. Facing the reality of drug-resistant tuberculosis in India; 2012. Available from: http://www.ncbi.nlm.nih.gov/books/NBK92617/pdf/TOC. pdf. Accessed July 30, 2020.

17. Spathelf B. Qualitative Structure-Activity Relationships of the Major Tyrocidines, Cyclic Decapeptides from Bacillus Aneurinolyticus. 2013:215.

18. Méndez-Lucio O, Naveja JJ, Vite-Caritino H, Prieto-Martínez FD, Medina-Franco JL. One drug for multiple targets: a computational perspective. J Mex Chem Soc. 2016;60(3):168-181. doi:10.29356/ jmcs.v60i3.100

19. World Health Organization. Malaria chapter 7. World Health Organization technical report series no 936; 2010. Available from: http://www.who.int/ith/ITH_chapter_7.pdf. Accessed July 30, 2020.

20. World malaria report 2018 ; 2018. Available from: https://www. who.int/malaria/publications/world-malaria-report-2018/en/. Accessed July 30, 2020.

21. Zininga T, Pooe OJ, Makhado PB, et al. Polymyxin B inhibits the chaperone activity of plasmodium falciparum Hsp70. Cell Stress Chaperones. 2017;22(5):707-715. doi:10.1007/s12192-017-0797-6

22. Opoku F, Govender PP, Pooe OJ, Simelane MBC. Evaluating iso-mukaadial acetate and ursolic acid acetate as plasmodium falciparum hypoxanthine-guanine-xanthine phosphoribosyltransferase inhibitors. Biomolecules. 2019;9(12):861. doi:10.3390/biom9120861

23. McMullan BJ, Mostaghim M. Prescribing azithromycin. Aust Prescr. 2015;38(3):87-90. doi:10.18773/austprescr.2015.030

24. Noedl H, Krudsood S, Chalermratana K, et al. Azithromycin combination therapy with artesunate or quinine for the treatment of uncomplicated plasmodium falciparum malaria in adults: a randomized, phase 2 clinical trial in Thailand. Clin Infect Dis. 2006;43(10):1264-1271. doi:10.1086/508175

25. Miller RS, Wongsrichanalai C, Buathong N, et al. Effective treatment of uncomplicated plasmodium falciparum malaria with azithromycin-quinine combinations: a randomized, dose-ranging study. Am J Trop Med Hyg. 2006;74(3):401-406. doi:10.4269/ ajtmh.2006.74.401

26. Mandal S, Mandal A, Johansson HE, Orjalo AV, Park MH. Depletion of cellular polyamines, spermidine and spermine, causes a total arrest in translation and growth in mammalian cells. Proc Natl Acad Sci US A. 2013;110(6):2169-2174. doi:10.1073/pnas.1219002110

27. Sagor GHM, Berberich T, Takahashi Y, Niitsu M, Kusano T. The polyamine spermine protects arabidopsis from heat stress-induced damage by increasing expression of heat shock-related genes. Transgenic Res. 2013;22(3):595-605. doi:10.1007/s11248-0129666-3 
28. Njunge JM, Mandal P, Przyborski JM, Boshoff A, Pesce E-R, Blatch GL. PFB0595w is a plasmodium falciparum $J$ protein that co-localizes with PfHsp70-1 and can stimulate its in vitro ATP hydrolysis activity. Int $J$ Biochem Cell Biol. 2015;62:47-53. doi:10.1016/j.biocel.2015.02.008

29. Pooe OJ, Köllisch G, Heine H, Shonhai A. Plasmodium falciparum heat shock protein 70 lacks immune modulatory activity. Protein Pept Lett. 2017;24(6):503-510. doi:10.2174/0929866524666170214141909

30. Porowińska D, Czarnecka J, Komoszyński M. Chaperones are necessary for the expression of catalytically active potato apyrases in prokaryotic cells. Appl Biochem Biotechnol. 2014;173 (6):1349-1359. doi:10.1007/s12010-014-0858-6

31. Murshid A, Gong J, Calderwood SK. The role of heat shock proteins in antigen cross presentation. Front Immunol. 2012;3:63. doi:10.3389/fimmu.2012.00063

32. Zininga T, Makumire S, Gitau GW, et al. Plasmodium falciparum hop (PfHop) interacts with the Hsp70 chaperone in a nucleotide-dependent fashion and exhibits ligand selectivity. PLoS One. 2015;10(8):e0135326. doi:10.1371/journal.pone.0135326

33. Makhoba XH, Pooe OJ, Mthembu MS. Molecular chaperone assisted expression systems: obtaining pure soluble and active recombinant proteins for structural and therapeutic purposes. $J$ Proteomics Bioinform. 2015;08(09):212-216. doi:10.4172/ jpb. 1000371

34. Hermayer KL, Dake A. Newer oral and noninsulin therapies to treat type 2 diabetes mellitus. Cleve Clin J Med. 2016;83(5):S18-S26. doi:10.3949/ccjm.83.s1.04

35. Huang J, Ofek G, Laub L, et al. Broad and potent neutralization of HIV-1 by a gp41-specific human antibody. Nature. 2012;491 (7424):406-412. doi:10.1038/nature11544

36. Pardoll DM. The blockade of immune checkpoints in cancer immunotherapy. Nat Rev Cancer. 2012;12(4):252-264. doi: $10.1038 / \mathrm{nrc} 3239$

37. Proschak E, Stark H, Merk D. Polypharmacology by design: a medicinal chemist's perspective on multitargeting compounds. $J$ Med Chem. 2019;62(2):420-444. doi:10.1021/acs.jmedchem. 8 b00760

38. Bolognesi ML, Cavalli A. Multitarget drug discovery and polypharmacology. ChemMedChem. 2016;11(12):1190-1192. doi:10.1002/cmdc.201600161

39. Konecny GE, Pegram MD, Venkatesan N, et al. Activity of the dual kinase inhibitor lapatinib (GW572016) against HER-2-overexpressing and trastuzumab-treated breast cancer cells. Cancer Res. 2006;66 (3):1630-1639. doi:10.1158/0008-5472.CAN-05-1182

40. Flinn IW, O'Brien S, Kahl B, et al. Duvelisib, a novel oral dual inhibitor of PI3K-d,g, is clinically active in advanced hematologic malignancies. Blood. 2018;131(8):877-887. doi:10.1182/blood2017-05-786566

41. Kucuksayan E, Ozben T. Hybrid compounds as multitarget directed anticancer agents. Curr Top Med Chem. 2016;17(8):907-918. doi:10.2174/1568026616666160927155515

42. Sharma A, Hill A, Kurbatova E, et al. Estimating the future burden of multidrug-resistant and extensively drug-resistant tuberculosis in India, the Philippines, Russia, and South Africa: a mathematical modelling study. Lancet Infect Dis. 2017;17(7):707-715. doi:10.1016/S1473-3099(17)30247-5

43. WHO. Global Tuberculosis Report 2017. 2017. doi:WHO/HTM/ $\mathrm{TB} / 2017.23$

44. Sejlitz T, Neujahr HY. Phenol hydroxylase from yeast. Eur J Biochem. 1987;170(1-2):343-349. doi:10.1111/j.1432-1033.1987.tb13705.x

45. Pooran A, Pieterson E, Davids M, Theron G, Dheda K. What is the cost of diagnosis and management of drug resistant tuberculosis in South Africa? PLoS One. 2013;8(1):e54587. doi:10.1371/journal. pone. 0054587

46. Abedinzadeh M, Gaeini M, Sardari S. Natural antimicrobial peptides against mycobacterium tuberculosis. $J$ Antimicrob Chemother. 2014;70(5):1285-1289. doi:10.1093/jac/dku570
47. Velayati AA, Farnia P, Masjedi MR, et al. Totally drug-resistant tuberculosis strains: evidence of adaptation at the cellular level. Eur Respir J. 2009;34(5):1202-1203. doi:10.1183/09031936.00081909

48. Gupta VK, Kumar MM, Bisht D, Kaushik A. Plants in our combating strategies against mycobacterium tuberculosis: progress made and obstacles met. Pharm Biol. 2017;55(1):1536-1544. doi:10.1080/13880209.2017.1309440

49. Lai MJ, Liu CC, Jiang SJ, et al. Antimycobacterial activities of endolysins derived from a mycobacteriophage, BTCU-1. Molecules. 2015;20(10):19277-19290. doi:10.3390/molecules201019277

50. Ayeni G, OJ Pooe P, M Singh S, N Nundkumar N, MBC Simelane S. Cytotoxic and antioxidant activities of selected south african medicinal plants. Pharmacogn J. 2019;11(6):1532-1539. doi:10.5530/pj.2019.11.234

51. Hatherley R, Brown DK, Musyoka TM, et al. SANCDB: a South African natural compound database. J Cheminform. 2015;7(1):1-9. doi:10.1186/s13321-015-0080-8

52. Lakshmanan D, Werngren J, Jose L, et al. Ethyl p-methoxycinnamate isolated from a traditional anti-tuberculosis medicinal herb inhibits drug resistant strains of mycobacterium tuberculosis in vitro. Fitoterapia. 2011;82(5):757-761. doi:10.1016/j.fitote.2011.03.006

53. Lawal TO, Adeniyi BA, Adegoke AO, Franzblau SG, Mahady GB. In vitro susceptibility of mycobacterium tuberculosis to extracts of eucalyptus camaldulensis and eucalyptus torelliana and isolated compounds. Pharm Biol. 2012;50(1):92-98. doi:10.3109/13880209.2011.625953

54. Thakur JP, Gothwal PP. Edible plants as a source of antitubercular agents. J Pharmacogn Phytochem. 2015;4(1):228-234.

55. Tekale $\mathrm{S}$, Mashele $\mathrm{S}$, Pooe $\mathrm{O}$, Thore $\mathrm{S}$ Biological role of chalcones in medicinal chemistry. IntechOpen; 2020. Available from: https://www. google $. \mathrm{com} / \mathrm{url}$ ? sa $=\mathrm{t} \& \mathrm{rct}=\mathrm{j} \& \mathrm{q}=\&$ esrc $=\mathrm{s} \&$ source $=$ web \&cd $=2 \& v e d=$ 2ahUKEwigvouT_43oAhWLSxUIHX-QCh8QFjABegQIAxAB\&url $=$ https $\% 3 \mathrm{~A} \% 2 \mathrm{~F} \% 2 \mathrm{Fcdn}$.intechopen.com $\% 2 \mathrm{Fpdfs} \% 2 \mathrm{~F} 71321$. pdf\&usg=AOvVaw2K2uNmFU9MwJYDpvBkF13V. Accessed July 30, 2020.

56. Molina-Salinas GM, Uc-Cachón AH, Peña-Rodríguez LM, DzulBeh ADJ, Graća-Medrano RME. Bactericidal effect of the leaf extract from musa spp. (AAB group, silk subgroup), cv. "manzano" against multidrug-resistant mycobacterium tuberculosis. $J$ Med Food. 2019;22(11):1183-1185. doi:10.1089/jmf.2019.0075

57. Multhoff G. Activation of natural killer cells by heat shock protein 70 . Int J Hyperthermia. 2002;18(6):576-585. doi:10.1080/026567302100 0017109

58. Li K, Schurig-Briccio LA, Feng X, et al. Multitarget drug discovery for tuberculosis and other infectious diseases. J Med Chem. 2014;57(7):3126-3129. doi:10.1021/jm500131s

59. Makobongo MO, Einck L, Peek RM, Merrell DS. In vitro characterization of the anti-bacterial activity of SQ109 against helicobacter pylori. PLoS One. 2013;8(7):1-16. doi:10.1371/journal.pone.0068917

60. Heinrich N, Dawson R, Bois J, et al. Early phase evaluation of SQ109 alone and in combination with rifampicin in pulmonary TB patients. J Antimicrob Chemother. 2014;70(5):1558-1566. doi:10. 1093/jac/dku553

61. TB Alliance. Pretomanid and BPaL regimen for treatment of highly-resistant tuberculosis. Oral Presentation. 2019. doi:10.1017/CBO9781107415324.004

62. Wellington S, Hung DT. The expanding diversity of mycobacterium tuberculosis drug targets. ACS Infect Dis. 2018;4(5):696-714. doi:10.1021/acsinfecdis.7b00255

63. Tang J, Wang B, Wu T, et al. Design, synthesis, and biological evaluation of pyrazolo[1,5-a]pyridine-3-carboxamides as novel antitubercular agents. ACS Med Chem Lett. 2015;6(7):814-818. doi:10.1021/acsmedchemlett.5b00176

64. Liu Y, Gao Y, Liu J, et al. The compound TB47 is highly bactericidal against mycobacterium ulcerans in a buruli ulcer mouse model. Nat Commun. 2019;10(1):1-9. doi:10.1038/s41467-01908464-y 
65. Njire $\mathrm{M}$, Wang N, Wang $\mathrm{B}$, et al. Pyrazinoic acid inhibits a bifunctional enzyme in mycobacterium tuberculosis. Antimicrob Agents Chemother. 2017;61(7):1-15. doi:10.1128/AAC.00070-17

66. Liu P, Yang Y, Tang Y, et al. Design and synthesis of novel pyrimidine derivatives as potent antitubercular agents. Eur $\mathrm{J}$ Med Chem. 2019;163:169-182. doi:10.1016/j.ejmech.2018.11.054

67. Schmelcher M, Donovan DM, Loessner MJ. Bacteriophage endolysins as novel antimicrobials. Future Microbiol. 2012;7 (10):1147-1171. doi:10.2217/fmb. 12.97

68. Hatfull GF. The Secret Lives of Mycobacteriophages. Vol. 82. 1st ed. Elsevier Inc.; 2012. doi:10.1016/B978-0-12-394621-8.00015-7

69. Haq IU, Chaudhry WN, Akhtar MN, Andleeb S, Qadri I. Bacteriophages and their implications on future biotechnology: a review. Virol J. 2012;9(1):9. doi:10.1186/1743-422X-9-9

70. Pirnay JP, Verbeken G, Ceyssens PJ, et al. The magistral phage. Viruses. 2018;10(2):1-7. doi:10.3390/v10020064

71. Schuch R, Lee HM, Schneider BC, et al. Combination therapy with lysin CF-301 and antibiotic is superior to antibiotic alone for treating methicillin-resistant staphylococcus aureus-induced murine bacteremia. J Infect Dis. 2014;209(9):1469-1478. doi:10.1093/ infdis/jit637

72. Thummeepak R, Kitti T, Kunthalert D, Sitthisak S. Enhanced antibacterial activity of acinetobacter baumannii bacteriophage ØАВР01 endolysin (LysABP-01) in combination with colistin. Front Microbiol. 2016;7(SEP):1-8. doi:10.3389/fmicb.2016.01402

73. Schuch R, Khan BK, Raz A, Rotolo JA, Wittekind M. Bacteriophage lysin CF-301, a potent antistaphylococcal biofilm agent. Antimicrob Agents Chemother. 2017;61(7):1-18. doi:10.1128/AAC.02666-16

74. Love M, Bhandari D, Dobson R, Billington C. Potential for bacteriophage endolysins to supplement or replace antibiotics in food production and clinical care. Antibiotics. 2018;7(1):17. doi:10.3390/antibiotics7010017

75. Rodríguez-Rubio L, Gutiérrez D, Donovan DM, Martínez B, Rodríguez A, García P. Phage lytic proteins: biotechnological applications beyond clinical antimicrobials. Crit Rev Biotechnol. 2015;8551(November):1-11. doi:10.3109/07388551.2014.993587

76. Herpers B. Endolysins: finding the answers to the problem of antibiotic resistance. Biomed Sci. 2015;(October):560-562.

77. Li Q, Zhou M, Fan X, Yan J, Li W, Xie J. Mycobacteriophage SWU1 gp39 can potentiate multiple antibiotics against mycobacterium via altering the cell wall permeability. Sci Rep. 2016;6 (March):1-14. doi:10.1038/srep28701

78. Dedrick RM, Guerrero-bustamante CA, Garlena RA, et al. Engineered bacteriophages for treatment of a patient with a disseminated drug-resistant mycobacterium abscessus. Nat Med. 2019;25(May):730-733. doi:10.1038/s41591-019-0437-z

79. Gondil VS, Chhibber S. Exploring potential of phage therapy for tuberculosis using model organism. Biomed Biotechnol Res J. 2018;9-15. doi:10.4103/bbrj.bbrj

80. Kalra S, Kalra B, Agrawal N, Unnikrishnan A. Understanding diabetes in patients with HIV/AIDS. Diabetol Metab Syndr. 2011;3(1):1-7. doi:10.1186/1758-5996-3-2

81. Samad F, Harris M, Puskas CM, et al. Incidence of diabetes mellitus and factors associated with its development in HIV-positive patients over the age of 50. BMJ Open Diabetes Res Care. 2017;5(1):1-10. doi:10.1136/bmjdrc-2017-000457

82. Viayna E, Sola I, Di Pietro O, Munoz-Torrero D. Human disease and drug pharmacology, complex as real life. Curr Med Chem. 2013;20(13):1623-1634. doi:10.2174/0929867311320130002

83. Shaw JE, Sicree RA, Zimmet PZ. Global estimates of the prevalence of diabetes for 2010 and 2030. Diabetes Res Clin Pract. 2010;87(1):4-14. doi:10.1016/j.diabres.2009.10.007

84. Target G, Facts F. Global NCD Target Reduce Premature. 2020.

85. Cefalo CMA, Cinti F, Moffa S, et al. Sotagliflozin, the first dual SGLT inhibitor: current outlook and perspectives. Cardiovasc Diabetol. 2019;18(1):1-14. doi:10.1186/s12933-019-0828-y
86. Egan A, Vella A. TTP399: an investigational liver-selective glucokinase (GK) activator as a potential treatment for type 2 diabetes. Expert Opin Investig Drugs. 2019;28(9):741-747. doi:10.1080/ 13543784.2019.1654993

87. McCall AL. Insulin therapy and hypoglycemia. Endocrinol Metab Clin North Am. 2012;41(1):57-87. doi:10.1016/j.ecl.2012.03.001

88. Yu X, Ye L, Zhang H, et al. Ginsenoside rb1 ameliorates liver fat accumulation by upregulating perilipin expression in adipose tissue of $\mathrm{db} / \mathrm{db}$ obese mice. J Ginseng Res. 2015;39(3):199-205. doi:10.1016/j.jgr.2014.11.004

89. Mabhida SE, Johnson R, Ndlovu M, Louw J, Opoku A, Mosa RA. Molecular basis of the anti-hyperglycemic activity of RA-3 in hyperlipidemic and streptozotocin-induced type 2 diabetes in rats. Diabetol Metab Syndr. 2019;11(1):1-5. doi:10.1186/s13098-0190424-z

90. Mabhida SE, Mosa RA, Penduka D, et al. A lanosteryl triterpene from protorhus longifolia improves glucose tolerance and pancreatic beta cell ultrastructure in type 2 diabetic rats. Molecules. 2017;22(8):1-11. doi:10.3390/molecules22081252

91. Mosa RA, Cele ND, Mabhida SE, Shabalala SC, Penduka D, Opoku AR. In vivo antihyperglycemic activity of a lanosteryl triterpene from Protorhus longifolia. Molecules. 2015;20 (7):13374-13383. doi:10.3390/molecules200713374

92. Machaba KE, Cobongela SZZ, Mosa RA, Oladipupo LA, Djarova TG, Opoku AR. In vivo anti-hyperlipidemic activity of the triterpene from the stem bark of protorhus longifolia (Benrh) engl. Lipids Health Dis. 2014;13(1):1-7. doi:10.1186/1476-511X-13-131

93. Sellamuthu PS, Arulselvan P, Kamalraj S, Fakurazi S, Kandasamy M. Protective nature of mangiferin on oxidative stress and antioxidant status in tissues of streptozotocin-induced diabetic rats. ISRN Pharmacol. 2013;2013:1-10. doi:10.1155/2013/750109

94. Min Q, Cai X, Sun W, et al. Identification of mangiferin as a potential glucokinase activator by structure-based virtual ligand screening. Sci Rep. 2017;7(November 2016):2-10. doi:10.1038/ srep44681

95. Bolognesi M. Polypharmacology in a single drug: multitarget drugs. Curr Med Chem. 2013;20(13):1639-1645. doi:10.2174/ 0929867311320130004

96. Agis-Torres A, Sollhuber M, Fernandez M, Sanchez-Montero JM. Multi-target-directed ligands and other therapeutic strategies in the search of a real solution for alzheimer's disease. Curr Neuropharmacol. 2014;12(1):2-36. doi:10.2174/1570159x1131 16660047

97. Geldenhuys W, Van der Schyf C. Rationally designed multi-targeted agents against neurodegenerative diseases. Curr Med Chem. 2013;20 (13):1662-1672. doi:10.2174/09298673113209990112

98. Viegas C, Bolzani VS, Pimentel LSB, et al. New selective acetylcholinesterase inhibitors designed from natural piperidine alkaloids. Bioorg Med Chem. 2005;13(13):4184-4190. doi:10. 1016/j.bmc.2005.04.030

99. Morphy R, Kay C, Rankovic Z. From magic bullets to designed multiple ligands. Drug Discov Today. 2004;9(15):641-651. doi:10.1016/S1359-6446(04)03163-0

100. Morphy R, Rankovic Z. Designed multiple ligands. An emerging drug discovery paradigm. J Med Chem. 2005;48(21):6523-6543. doi: $10.1021 / \mathrm{jm} 058225 \mathrm{~d}$

101. Wertheimer A. The economics of polypharmacology: fixed dose combinations and drug cocktails. Curr Med Chem. 2013;20 (13):1635-1638. doi:10.2174/0929867311320130003

102. Dias KST, De Paula CT, Riquiel MM, et al. Recent applications of the multi-target directed ligands approach for the treatment of alzheimer's disease. Rev Virtual De Quimica. 2015;7(2):609-648. doi:10.5935/1984-6835.20150027

103. Manssour Fraga C, Barreiro E. New insights for multifactorial disease therapy: the challenge of the symbiotic drugs. Curr Drug Ther. 2008;3(1):1-13. doi:10.2174/157488508783331225 
104. Lin HH, Zhang L, Yan R, Lu JJ, Hu Y. Network analysis of drug-target interactions: a study on FDA-approved new molecular entities between 2000 to 2015. Sci Rep. 2017;7(1). doi:10.1038/ s41598-017-12061-8

105. Lansbury PT. Back to the future: the 'old-fashioned' way to new medications for neurodegeneration. Nat Rev Neurosci. 2004;10(7): S51. doi:10.1038/nrn1435

106. Cavalli A, Bolognesi ML, Minarini A, et al. Multi-target-directed ligands to combat neurodegenerative diseases. J Med Chem. 2008;51(3):347-372. doi:10.1021/jm7009364

107. Bajic V, Milovanovic E, Spremo-Potparevic B, et al. Treatment of alzheimer's disease: classical therapeutic approach. Curr Pharm Anal. 2016;12(2):82-90. doi:10.2174/1573412911666150611184740

108. Viegas FPD, Simões MCR, Da Rocha MD, Castelli MR, Moreira MS, Junior CV. Alzheimer's disease: characterization, evolution and implications of the neuroinflammatory process. Rev Virtual De Quimica. 2011;3(4):286-306. doi:10.5935/19846835.20110034

109. Divino da Rocha M, Pereira Dias Viegas F, Cristina Campos H, et al. The role of natural products in the discovery of new drug candidates for the treatment of neurodegenerative disorders ii: alzheimers disease. CNS Neurol Disord Drug Targets. 2011;10 (2):251-270. doi:10.2174/187152711794480429

110. Munoz-Torrero D. Editorial (hot topic: complexity against complexity: multitarget drugs). Curr Med Chem. 2013;20 (13):1621-1622. doi:10.2174/0929867311320130001

111. Youdim $\mathrm{MBH}$, Buccafusco JJ. Multi-functional drugs for various CNS targets in the treatment of neurodegenerative disorders. Trends Pharmacol Sci. 2005;26(1):27-35. doi:10.1016/j.tips.2004.11.007

112. Carreiras M, Mendes E, Perry M, Francisco A, Marco-Contelles J. The multifactorial nature of alzheimer's disease for developing potential therapeutics. Curr Top Med Chem. 2013;13 (15):1745-1770. doi:10.2174/15680266113139990135

113. Csermely P, Ágoston V, Pongor S. The efficiency of multi-target drugs: the network approach might help drug design. Trends Pharmacol Sci. 2005;26(4):178-182. doi:10.1016/j.tips.2005.02.007

114. Giulia N, Simona S, Maria D, Simona R. Oxidative stress, mitochondrial abnormalities and proteins deposition: multitarget approaches in alzheimer's disease. Curr Top Med Chem. 2017;17 (27). doi:10.2174/1568026617666170607114232
115. Wang T, Liu X, Guan J, et al. Advancement of multi-target drug discoveries and promising applications in the field of alzheimer's disease. Eur J Med Chem. 2019;169:200-223. doi:10.1016/j. ejmech.2019.02.076

116. Zhan P, Liu X. Rationally designed multitarget anti-HIV agents. Curr Med Chem. 2013;20(13):1743-1758. doi:10.2174/092986731132013 0011

117. Rodrigues Simoes M, Dias Viegas F, Moreira M, et al. Donepezil: an important prototype to the design of new drug candidates for alzheimer's disease. Mini Rev Med Chem. 2014;14(1):2-19. doi:10.2174/1389557513666131119201353

118. León R, Garcia AG, Marco-Contelles J. Recent advances in the multitarget-directed ligands approach for the treatment of alzheimer's disease. Med Res Rev. 2013;33(1):139-189. doi:10.1002/ med.20248

119. Cuny GD. Neurodegenerative diseases: challenges and opportunities. Future Med Chem. 2012;4(13):1647-1649. doi:10.4155/fmc.12.123

120. Simone Tranches Dias K, Viegas C. Multi-target directed drugs: a modern approach for design of new drugs for the treatment of alzheimer's disease. Curr Neuropharmacol. 2014;12(3):239-255. doi:10.2174/1570159x1203140511153200

121. Crews L, Masliah E. Molecular mechanisms of neurodegeneration in alzheimer's disease. Hum Mol Genet. 2010;19(R1):R12-R20. doi: $10.1093 / \mathrm{hmg} / \mathrm{ddq} 160$

122. Kumar K, Kumar A, Keegan RM, Deshmukh R. Recent advances in the neurobiology and neuropharmacology of alzheimer's disease. Biomed Pharmacother. 2018;98:297-307. doi:10.1016/j.biopha.2017.12.053

123. Shi S, Wang Z, Qiao Z. The multifunctional anti-inflammatory drugs used in the therapy of alzheimer's disease. Curr Med Chem. 2013;20 (20):2583-2588. doi:10.2174/0929867311320200006

124. Divari S, Valetti F, Caposio P, et al. The oxygenase component of phenol hydroxylase from acinetobacter radioresistens S13. Eur J Biochem. 2003;270(10):2244-2253. doi:10.1046/j.1432-1033.2003. 03592.x

125. Nolan LC, O’Connor KE. Dioxygenase- and monooxygenase-catalysed synthesis of cis-dihydrodiols, catechols, epoxides and other oxygenated products. Biotechnol Lett. 2008;30(11):1879-1891. doi:10.1007/ s10529-008-9791-5
Drug Design, Development and Therapy

\section{Publish your work in this journal}

Drug Design, Development and Therapy is an international, peerreviewed open-access journal that spans the spectrum of drug design and development through to clinical applications. Clinical outcomes, patient safety, and programs for the development and effective, safe, and sustained use of medicines are a feature of the journal, which has also been accepted for indexing on PubMed Central. The manuscript management system is completely online and includes a very quick and fair peer-review system, which is all easy to use. Visit http://www. dovepress.com/testimonials.php to read real quotes from published authors. 